\title{
O ensino de Física e o Modelo Capitalista
}

\author{
The teaching of Physics and the Capitalist Model \\ La enseñanza de la Física y el Modelo Capitalista
}

Recebido: 08/08/2021 | Revisado:14/08/2021 | Aceito: 16/08/2021 | Publicado: 18/08/2021

Caio Araujo Cruz

ORCID: https://orcid.org/0000-0002-6864-5222 Instituto Federal de Educação, Ciência e Tecnologia do Ceará, Brasil E-mail: caio.araujo.cruz@hotmail.com

Erica Jeani Costa de Santana e Silva

ORCID: https://orcid.org/0000-0003-2042-3732 Instituto Federal de Educação, Ciência e Tecnologia do Ceará, Brasil E-mail: ericajeanicosta@gmail.com

Gilvandenys Leite Sales

ORCID: https://orcid.org/0000-0002-6060-2535 Instituto Federal de Educação, Ciência e Tecnologia do Ceará, Brasil

E-mail: denyssales@ifce.edu.br

Alisandra Cavalcante Fernandes de Almeida

ORCID: https://orcid.org/0000-0002-7066-1504 Instituto Federal de Educação, Ciência e Tecnologia do Ceará, Brasil E-mail: alisandra.cavalcante@ifce.edu.br

\begin{abstract}
Resumo
O ensino de física no Brasil passa por algumas limitações quanto ao uso de metodologias inovadoras, é constantemente apontado que a física é abordada a partir de uma metodologia tradicional de ensino, metodologia esta que é muito discutida e apontada como problemática para o aprendizado. Desta forma, o seguinte artigo apresenta uma revisão de literatura narrativa acerca da influência do modelo social capitalista no ensino de física, onde busca discutir as problemáticas que envolvem o ensino de física atual e buscar sua relação direta ou indireta com o modelo capitalista de sociedade apresentado por Karl Marx, apresentar um debate sobre a influência deste modelo nos objetivos da escola, no tipo de homem e cidadão que esta escola inserida no modelo capitalista busca formar e nas tendências pedagógicas utilizadas dentro da escola atual e no ensino de física. Trazendo como resultado uma reflexão sobre as problemáticas que afetam alunos, professores e que se estruturam a partir deste modelo de sociedade.
\end{abstract}

Palavras-chave: Ensino de Física; Modelo capitalista; Ensino tradicional.

\begin{abstract}
The teaching of physics in Brazil has some limitations regarding the use of innovative methodologies, it is constantly pointed out that physics is approached from a traditional teaching methodology, a methodology that is widely discussed and pointed out as problematic for learning. Thus, the following article presents a narrative literature review on the influence of the capitalist social model on physics education, where it seeks to discuss the issues surrounding the current physics teaching and seek its direct or indirect relationship with the capitalist model of society presented by Karl Marx, to present a debate on the influence of this model on the school's goals, on the type of man and citizen that this school, inserted in the capitalist model, seeks to form and on the pedagogical trends used within the current school and in the teaching of physics. Bringing as a result a reflection on the problems that affect students, teachers and that are structured from this model of society.
\end{abstract}

Keywords: Physics teaching; Capitalist model; Traditional teaching.

\section{Resumen}

La enseñanza de la física en Brasil tiene algunas limitaciones en cuanto al uso de metodologías innovadoras, se señala constantemente que la física se aborda desde una metodología de enseñanza tradicional, metodología que es ampliamente discutida y señalada como un problema para el aprendizaje. Así, el siguiente artículo presenta una revisión de la literatura narrativa sobre la influencia del modelo social capitalista en la educación física, donde busca discutir los temas que rodean la enseñanza de la física actual y buscar su relación directa o indirecta con el modelo capitalista de sociedad presentado por. Karl Marx, para presentar un debate sobre la influencia de este modelo en los fines de la escuela, sobre el tipo de hombre y ciudadano que esta escuela, insertada en el modelo capitalista, busca formar y sobre las corrientes pedagógicas utilizadas dentro de la escuela actual y en la enseñanza de la física. Trayendo como resultado una reflexión sobre los problemas que afectan a los alumnos, profesores y que se estructuran desde este modelo de sociedad.

Palabras clave: Enseñanza de la Física; Modelo capitalista; Enseñanza tradicional. 


\section{Introdução}

É possível observar na literatura que o ensino de Física passa por diversas problemáticas, várias delas no âmbito estrutural, por falta de investimento em professores, qualificação e materiais pedagógicos, como um laboratório equipado, por exemplo. Mas, além dessas problemáticas, um dos vilões quando se fala da problemática do ensino de Física é o modelo tradicional de ensino, apontado por diversos autores como Moreira (2010, 2018), Freire (1988), Mizukami (1986), Saviani (1999). De acordo com Moreira (2010).

aprendizagem mecânica, aquela praticamente sem significado, puramente memorística, que serve para as provas e é esquecida, apagada, logo após. Em linguagem coloquial, a aprendizagem mecânica é a conhecida decoreba, tão utilizada pelos alunos e tão incentivada na escola. (Moreira, 2010, p.12).

Ainda segundo Moreira (2018):

Os conteúdos curriculares não vão além da Mecânica Clássica e são abordados da maneira mais tradicional possível, totalmente centrada no professor, baseada no modelo de narrativa criticado por Finkel (1999), na educação bancária de Freire (2007), no comportamentalismo de Skinner (1972). (p.73).

Já Freire (1988) define esse tipo de educação como bancária, onde a educação se resume ao ato de depositar, transferir, transmitir valores e informações. O processo de ensino e aprendizagem, que deveria levar os alunos à sua formação pessoal, social e intelectual, torna-se um processo de simples memorização e preparação para os testes (provas internas e externas) e em vestibulares e assume como seu objetivo a ampla aprovação e a entrada de alunos no ensino superior.

Este método é baseado apenas na transmissão das informações acumuladas pelo professor para o aluno através da fala, da memorização, das provas e exercícios. O aluno é colocado em uma posição passiva no processo de aprendizagem e o professor é o protagonista neste processo.

Conforme Mizukami (1986)

O ensino, em todas as suas formas, nessa abordagem, será centrado no professor. Esse tipo de ensino volta-se para o que é externo ao aluno: o programa, as disciplinas, o professor. O aluno apenas executa prescrições que lhe são fixadas por autoridades exteriores. (Mizukami, 1986, p. 8).

Este modelo de ensino mostra-se ineficiente para a aprendizagem dos alunos, os retira do papel de protagonistas no seu processo de aprendizagem e prejudica o desenvolvimento que estes poderiam ter. Segundo Rego (1995), sob a perspectiva dos postulados de Vygostky, temos que:

O ensino verbalista, baseado na transmissão oral de conhecimentos por parte do professor, assim como as práticas espontaneístas, que abdicam de seu papel de desafiar e intervir no processo de apropriação de conhecimentos por parte das crianças e adolescentes, são, na perspectiva vygotskiana, além de infrutíferos, extremamente inadequados. Seus postulados apontam para a necessidade de criação de melhores condições na escola, para que todos os alunos tenham acesso às informações e experiências e possam efetivamente aprender. (Rego, 1995, p. 106).

Então, pode-se perguntar, por que a metodologia tradicional de ensino ainda permanece sendo utilizada pela maioria esmagadora de professores de física? Para responder esta pergunta, é necessário entender dois pontos importantes. O primeiro ponto são as tendências pedagógicas vigentes; e o segundo ponto é como a escola reproduz o modelo social vigente. 


\title{
2. Metodologia
}

Este artigo apresenta uma revisão literária narrativa definido por Rother (2007) como "publicações amplas, apropriadas para descrever e discutir o desenvolvimento ou o "estado da arte" de um determinado assunto, sob o ponto de vista teórico ou contextual". O autor ainda reitera que esta metodologia constitui uma análise da literatura sob o ponto de vista crítico e pessoal do autor. Desta forma, o artigo buscará relacionar as problemáticas do ensino de física com as estruturas capitalistas apontadas na literatura de Karl Marx.

\section{Resultados e Discussão}

\subsection{Tendências Pedagógicas:}

Atualmente duas tendências pedagógicas ganham destaque, são elas as tendências pedagógicas liberais e tendências pedagógicas progressistas. A pedagogia liberal, que se subdivide em tradicional, renovada progressista, renovada não-diretiva e tecnicista. E a pedagogia progressista, que se subdivide em libertadora, libertária e crítico-social dos conteúdos.

Libâneo (1990) define a pedagogia liberal como

\begin{abstract}
A pedagogia liberal sustenta a ideia de que a escola tem por função preparar os indivíduos para o desempenho de papéis sociais, de acordo com as aptidões individuais. Para isso, os indivíduos precisam aprender a adaptar-se aos valores e às normas vigentes na sociedade de classes, através do desenvolvimento da cultura individual. A ênfase no aspecto cultural esconde a realidade das diferenças de classes, pois, embora difunda a ideia de igualdade de oportunidades, não leva em conta a desigualdade de condições. Historicamente, a educação liberal iniciou-se com a pedagogia tradicional e, por razões de recomposição da hegemonia da burguesia, evoluiu para a pedagogia renovada (também denominada escola nova ou ativa), o que não significou a substituição de uma pela outra, pois ambas conviveram e convivem na prática escolar. (Libâneo, 1990, p. 6).
\end{abstract}

Já a pedagogia progressista é definida por Libâneo (1990) como "tendências que, partindo de uma análise crítica das realidades sociais, sustentam implicitamente as finalidades sociopolíticas da educação.” Desta forma, a tendência progressista tem uma posição antagônica a tendência liberal pois busca a formação do aluno, não apenas interessada no acúmulo de conteúdos, mas junto a isto, trazer as questões sociopolíticas em que a escola e os alunos se encontram inseridos.

Dentro desse contexto, a maioria das escolas brasileiras, públicas e privadas, tem adotado um modelo de educação tido como tradicional, que teve seu início, segundo Saviani (1999), a partir da revolução industrial.

O que estou querendo enfatizar com isto é que esse método tradicional foi constituído após a revolução industrial, contrariamente, portanto, ao argumento que os escolanovistas comumente levantam de que a revolução industrial transformou a sociedade, determinou uma sociedade não mais estática, em mudança contínua, que essa revolução industrial, que tem seu fundamento na ciência, não teve sua contrapartida na educação, que continuou sendo précientífica, seguindo lemas medievais. (Saviani, 1999, p. 54).

Este modelo de ensino se enquadra como uma pedagogia liberal, conforme mostra Libâneo (1990).

A doutrina liberal apareceu como justificativa do sistema capitalista que, ao defender a predominância da liberdade e dos interesses individuais na sociedade, estabeleceu uma forma de organização social baseada na propriedade privada dos meios de produção, também denominada saciedade de classes. A pedagogia liberal, portanto, é uma manifestação própria desse tipo de sociedade. (Libâneo. 1990. p, 6).

Ainda conforme Libâneo (1996) em seu trabalho seguinte.

Na tendência tradicional, a pedagogia se caracteriza por acentuar o ensino humanístico, de cultura geral, no qual aluno é educado para atingir, pelo próprio esforço, sua plena realização como pessoa. Os conteúdos, os procedimentos didáticos, a relação professor-aluno não têm nenhuma relação com o cotidiano do aluno e muito menos com as 
realidades sociais. É a predominância da palavra do professor, das regras impostas, do cultivo exclusivamente intelectual. (LIBÂNEO, 1996, P. 7).

Esse modelo de ensino é baseado na exposição dos conteúdos definidos por um currículo e ajustados conforme a necessidade de cada escola e cada sala de aula, além da realidade escolar, e na repetição mecânica destes conteúdos pelos alunos em provas e testes.

No entanto, esse ensino dito tradicional se estruturou através de um método pedagógico, que é o método expositivo, que todos conhecem, todos passaram por ele, e muitos estão passando ainda, cuja matriz teórica pode ser identificada nos cinco passos formais de Herbart. Esses passos, que são o passo da preparação, o passo da apresentação, da comparação e assimilação, da generalização e, por último, da aplicação, correspondem ao esquema do método científico indutivo, tal como fora formulado por Bacon, método que podemos esquematizar em três momentos fundamentais: a observação, a generalização e a confirmação. (SAVIANI, 1999, p. 54).

Nesse modelo de ensino, o aluno tem um papel passivo na aprendizagem, o professor é o centro de todo conhecimento. Conforme Mizukami (1986).

O ensino, em todas as suas formas, nessa abordagem, será centrado no professor. Esse tipo de ensino volta-se para o que é externo ao aluno: o programa, as disciplinas, o professor. O aluno apenas executa prescrições que lhe são fixadas por autoridades exteriores. (Mizukami, 1986, p. 8).

Moreira define esse tipo de ensino como

No entanto, a aprendizagem que mais ocorre na escola é outra: a aprendizagem mecânica, aquela praticamente sem significado, puramente memorística, que serve para as provas e é esquecida, apagada, logo após. Em linguagem coloquial, a aprendizagem mecânica é a conhecida decoreba, tão utilizada pelos alunos e tão incentivada na escola. (Moreira, 2010, p. 12).

Com esse modelo de ensino, tem-se uma metodologia avaliativa que consiste na reprodução de conceitos, que não avalia o real aprendizado do educando. Conforme aponta Mizukami (1986)

A avaliação é realizada predominantemente visando a exatidão da reprodução do conteúdo comunicado em sala de aula. Mede-se, portanto, pela quantidade e exatidão de informações que se consegue reproduzir. Daí a consideração de provas, exames, chamadas orais, exercícios etc., que evidenciem a exatidão da reprodução da informação. $\mathrm{O}$ exame passa a ter um fim em si mesmo e o ritual é mantido. As notas obtidas funcionam, na sociedade, como níveis de aquisição do patrimônio cultural. (MIZUKAMI, 1986, p. 17).

Desta forma, pode ser observado que ao se utilizar majoritariamente da metodologia tradicional, escolas e professores utilizam de um modelo pedagógico liberal, que busca apenas preparar os alunos intelectualmente a partir do acúmulo de informações e negligencia quase que totalmente o papel social que o aluno deve exercer enquanto cidadão formado.

Então deve-se pensar qual o motivo das escolas ainda adotarem o ensino tradicional. Para que se entenda essa questão, é necessário ter em mente que a escola tem um papel fundamental na reprodução do espaço social em que está inserida.

\subsection{Escola e a Reprodução do Modelo Social:}

A escola tem um papel social fundamental para a formação de cidadãos com capacidade de contribuir e resolver problemas inerentes às questões que envolvem a sociedade, como problemas ambientais, desigualdade social, preconceito, tem a função de apresentar ao aluno o conhecimento científico formalmente, é um espaço social onde são desenvolvidas relações entre pessoas e oportunidade de ascensão para muitos. 
Na perspectiva de Vygotsky sob o olhar da autora Teresa Cristina Rego (1995). "A escola tem um papel diferente e insubstituível, na apropriação pelo sujeito da experiência culturalmente acumulada. Justamente por isso, ela representa o elemento imprescindível par a realização plena do desenvolvimento dos indivíduos (que vivem em sociedades escolarizadas) $[\ldots] . "$

Contudo, alguns autores afirmam que a escola terá um papel fundamental para reproduzir o modelo social vigente em que está inserida.

Na visão de Mészáros (2005), a educação tornou-se instrumento que fornece os conhecimentos e a mão de obra necessária à maquinaria produtiva do sistema capitalista, além de transmitir "um quadro de valores que legitima os interesses dominantes"

Conforme afirma Saviani (2013)

Dizer, então, que a educação é um ato político significa dizer que a educação não está divorciada das características da sociedade; ao contrário, ela é determinada pela sociedade na qual está inserida. E, quando a sociedade é dividida em classes cujos interesses são antagônicos, a educação serve a interesses de uma ou de outra das classes fundamentais. (Saviani, 2013, p.2)

Já segundo Bonnewitz (2005) a escola está "longe de reduzir as desigualdades sociais, contribui para reproduzi-las". Mas, em que modelo social a escola está inserida atualmente? Sabe-se que, não só o Brasil, mas a maior parte do mundo está inserido no modelo capitalista, logo é necessário entender como se dá esse modelo para se entender a educação dentro desta sociedade.

O modelo capitalista tem seu começo a partir do momento em que a estrutura feudal já não mais atendia as necessidades da classe burguesa que estava em ascendência, necessidades estas que surgem com a possibilidade de grandes expansões comerciais, segundo Marx

A descoberta da américa, a circunavegação da África abriram um novo campo de ação à burguesia emergente. Os mercados das Índias Orientais e da china, a colonização da América, o comércio colonial, o incremento dos meios de troca e das mercadorias em geral imprimiram ao comércio, à indústria e à navegação um impulso desconhecido até então; e, por conseguinte, desenvolveram rapidamente o elemento revolucionário da sociedade feudal em decomposição. (Marx, 1848, p. 41).

Entretanto, em decorrência da expansão do comércio, o modo de produção também já não era suficiente, então Marx (1848) afirma que a manufatura se tornou insuficiente, então o vapor e a máquina revolucionaram a produção industrial.

Assim, com a expansão do comércio, a burguesia, que antes fora oprimida no sistema feudal, agora torna-se a classe dominante, e com ela traz grandes consequências ao modelo de vida e de sociedade. Se faz importante salientar que, neste ponto, a classe burguesa teve papel de grande importância, pois exerceu um caráter revolucionário na história, derrubando o modelo feudal vigente.

Segundo Marx (1848)

A burguesia desempenhou na história um papel iminentemente revolucionário. Onde quer que tenha conquistado o poder, a burguesia destruiu as relações feudais, patriarcais e idílicas. Rasgou todos os complexos e variados laços que prendiam o homem feudal a seus "superiores naturais “, para só deixar subsistir, de homem para homem, o laço do frio interesse, as duras exigências do "pagamento à vista". Afogou os fervores sagrados da exaltação religiosa, do entusiasmo cavalheiresco, do sentimentalismo pequeno-burguês nas águas geladas do cálculo egoísta. Fez da dignidade pessoal um simples valor de troca; substituiu as numerosas liberdades, conquistadas duramente, por uma única liberdade sem escrúpulos: a do comercio. (Marx, 1848, p. 42). 
Assim, a burguesia avança em sua expansão por todo globo, mudando os modelos estabelecidos anteriormente pelo novo modelo que satisfazia a necessidade de expandir o mercado, e se consolida cada vez mais como classe dominante. Com esse efeito, não só o modelo de comércio, mas a cultura e os modelos sociais da burguesia se expandem por todo o globo e assim, se percebem os primeiros indícios do que hoje é chamado de globalização, Marx (1848) aponta

No lugar do antigo isolamento de regiões e nações auto-suficientes, desenvolvem-se um intercâmbio universal e uma universal dependência das nações. E isto se refere tanto à produção material como à produção intelectual. As criações intelectuais de uma nação tornam-se patrimônio comum. (Marx, 1848, p.43).

A burguesia tem seu importante papel na expansão desse novo modelo de produção e de expansão comercial, mas também é necessário falar que é consequência do desenvolvimento da burguesia, por mais contraditório que possa parecer, o surgimento da classe antagônica, o proletariado. Conforme Marx (1848)

Com o desenvolvimento da burguesia, isto é, do capital, desenvolve- se também o proletariado, a classe dos operários modernos, os quais só vivem enquanto têm trabalho e só tem trabalho enquanto seu trabalho aumento o capital. Esses operários, constrangidos a vender- se a retalho, são mercadoria, artigo de comércio como qualquer outro; em consequência, estão sujeitos a todas as vicissitudes da concorrência, a todas as flutuações do mercado. (Marx, 1848, p.46).

Trabalho este, desenvolvido pela classe do proletariado, que é condição inerente ao homem. Para Marx (1996)

Antes de tudo, o trabalho é um processo entre o homem e a Natureza, um processo em que o homem, por sua própria ação, media, regula e controla seu metabolismo com a Natureza. Ele mesmo se defronta com a matéria natural como uma força natural. Ele põe em movimento as forças naturais pertencentes a sua corporalidade, braços e pernas, cabeça e mão, a fim de apropriar-se da matéria natural numa forma útil para sua própria vida. Ao atuar, por meio desse movimento, sobre a Natureza externa a ele e ao modificá-la, ele modifica, ao mesmo tempo, sua própria natureza (Marx, 1996, p. 297).

Bizerra salienta também que

O trabalho é o único pressuposto para a existência humana, expressando-se, desta feita, como matriz ontológica do ser social. Síntese entre teleologia (prévio planejamento, estabelecimento de fins e escolha entre alternativas) e causalidade (o ser natural, regido por leis de tipo causal), ele é uma atividade intencional que faz parte, embora de modos diferentes, da vida do homem em toda e qualquer forma de sociabilidade e se afirmar, dia a dia, numa escala milenar, como uma relação sociometabólica do homem com a natureza. (Bizerra, 2017, p. 1).

Porém, nota-se que a relação entre burguês e proletário, ou capitalista e trabalhador, é uma relação de exploração, relação essa que consiste na expropriação do produto do trabalho do trabalhador pelo capitalista, no lucro do capitalista e pelo repasse mínimo deste lucro (salário) ao trabalhador.

É importante salientar que, nas sociedades modernas, existem leis e projetos que defendem os trabalhadores, que tentam minimizar os efeitos da exploração e evitar situações análogas, ou iguais, a escravidão. Contudo, não se pode ficar alheio ao fato de que as novas sociedades e leis se estruturam conforme os interesses e as necessidades da classe dominante na sociedade capitalista.

O trabalho e sua expropriação são de suma importância dentro do molde capitalista de mercado, pois é ele que proporciona valor ao produto. Segundo Neto (2015)

[...]. É o tempo de trabalho excedente que agrega mais valor ao produto final. O trabalho objetivado tanto reproduz valor existente quanto agrega novo valor ao produto. $\mathrm{O}$ trabalho tanto altera a composição da matéria-prima, pela recorrência dos instrumentos dados, quanto agrega novo valor. $\mathrm{O}$ trabalho vivo conserva o valor e cria novo valor. $\mathrm{O}$ 
que para o capitalista é mais-valia, para o trabalhador é mais- trabalho, é trabalho além do necessário para a reprodução da existência empírica do trabalhador. (Neto, 2015, p.61).

Assim, a sociedade capitalista se estrutura como uma sociedade de relações de exploração, onde o capitalista explora o trabalhador, o burguês explora o proletário, mas para que isso aconteça, Marx (1848) aponta que "para oprimir uma classe é preciso poder garantir-lhe condições tais que lhe permitam pelo menos uma existência servil.

Tais condições conferem ao homem inserido na sociedade uma nova visão de si. Tais homens trabalhadores são tratados também mercadorias dentro do capital, contudo, é uma mercadoria viva, um “capital vivo”. Segundo Marx (1932)

Mas, o trabalhador tem a infelicidade de ser um capital vivo e, portanto, carente (bedürftig), que, a cada momento em que não trabalha, perde seus juros e, com isso, sua existência. Como capital, o valor do trabalhador aumenta no sentido da procura e da oferta e, também, fisicamente a sua existência (Dasein), a sua vida, se torna e é sabida como oferta de mercadoria, tal como qualquer outra mercadoria. (Marx, 1932, p. 91).

Dessa forma, o homem é definido apenas enquanto trabalhador, e apenas consegue se definir quando trabalha, esta condição se torna inerente ao homem durante seu desenvolvimento inserido dentro deste modelo de sociedade, sendo extremamente difícil desligá-lo dessa visão de si e do outro.

Como consequência desse exposto, o homem também passa a se definir pelo seu "tesouro ", pela quantidade que consegue acumular, e quanto "poder "esse tesouro o confere. "A quantidade de dinheiro se torna cada vez mais seu único atributo poderoso; assim como ele reduz todo o ser à sua abstração, reduz-se ele em seu próprio movimento a ser quantitativo. “(Marx, 1932) Logo, o homem se define, e define o outro, dentro dessa sociedade, pela quantidade que consegue acumular, pelo quanto trabalho consegue realizar, transforma suas definições apenas à quantidade de dinheiro que possui, abre mão do seu ser, do que o define como pessoa, para definir-se apenas como trabalhador e acumulador. Marx (1932) expõe da seguinte forma.

Quanto menos comeres, beberes, comprares livros, fores ao teatro, ao baile, ao restaurante, pensares, amares, teorizares, cantares, pintares, esgrimires etc., tanto mais tu poupas, tanto maior se tornará o teu tesouro, que nem as traças nem o roube corroem, teu capital. [...] E tudo aquilo que tu não podes, pode o teu dinheiro: ele pode comer, beber, ir ao baile, ao teatro, sabe de arte, de erudição, de raridades históricas, de poder político, pode viajar pode apropriar-se disso tudo para ti; pode comprar tudo isso; ele é a verdadeira capacidade. (Marx, 1932, p.141).

Consequente a essa visão de homem atribuída dentro da sociedade capitalista, há uma constante procura por melhores salários, condições melhores, maior conforto, em contraponto, para alcançar tais objetivos, é deixado de lado o bem-estar pessoal, o sentir-se bem, o manter-se saudável e entender-se como ser humano e sua posição dentro do meio.

Atualmente, em detrimento dos avanços tecnológicos e científicos, há uma vasta lista de profissões onde pode-se atuar. Diferentes pessoas têm diferentes aptidões e diferentes habilidades para atuar dentro do mercado de trabalho, contudo, essa vastidão de opções "some" no momento em que se coloca como definição do homem apenas a necessidade de acumular capital, então, pessoas com diferentes habilidades e necessidades são direcionadas apenas a aquelas profissões em que se tem maior retorno financeiro, e não que completaria a pessoa como ser, que desenvolveria suas aptidões pessoais e intelectuais.

É importante salientar que, numa sociedade de classes, mesmo que existam essas profissões tidas como "melhores “, que são as profissões que possuem maior prestígio social, e por consequência, maiores salários, as classes mais baixas são, de várias formas, impedidas de alcançar tais profissões, mantendo assim a distância clara entre opressores e oprimidos, explorador e explorado, burguês e proletário. 
Nota-se também que, com os avanços das tecnologias, tornou-se necessária uma maior especialização para se encaixar dentro do mercado de trabalho atual, há uma maior exigência por cursos superiores ou especializações para certos tipos de profissões, assim, colocando em evidência o conceito da teoria do capital humano. Segundo Andrade (2010)

A Teoria do Capital Humano surgiu na década de 1950 com os estudos de Theodore W. Schultz (1961, 1964, 1968, 1973), na época professor da Universidade de Chicago, e foi desenvolvido e popularizado por Gary S. Becker (1993). Esses autores tratam de um tipo diferente de capital, para eles escolaridade, cursos, gasto médicos e palestras também são considerados capitais pois melhoram a saúde e o rendimento dos indivíduos. Logo gastos com educação, treinamento e saúde, entre outros, podem ser considerados como investimentos em capital. Esses fatores produzem Capital Humano, pois não é possível separar o indivíduo de seu conhecimento, saúde ou habilidades da mesma forma que podemos mover o capital financeiro e físico. (Andrade, 2010, p. 7).

Então, a utilização a metodologia tradicional de ensino se justifica por se qualificar como uma metodologia que auxilia com a estruturação do modelo capitalista, uma metodologia que não incentiva o aluno a questionar, criar e debater, o aluno é apenas incentivado a repetir o que lhe é passado, reproduzir mecanicamente o que é ensinado, perpetuando assim os ideais vigentes.

Desta forma, a escola assume o papel de preparar o aluno para garantir um emprego no mercado de trabalho, e de tentar garantir a aprovação dentro de uma universidade pública ou faculdade privada, para que se possa competir com outros profissionais.

Assim, a formação educacional passa também a ser um valor capaz de produzir lucro e, por consequência, ranqueia cada pessoa conforme seu grau de formação e sua capacidade de produzir capital. Andrade (2010) ressalta que "Diferenças na educação dos indivíduos, ou seja, no seu estoque de Capital Humano, são responsáveis pelos diferentes níveis de salários dos trabalhadores"

Contudo, tais exigências trazem consigo uma maior cobrança e pressão sobre o indivíduo, como apontam Maia, Lima e Maia (2015)

Entretanto, o desprezo assola o universo do trabalhador e traz consequências drásticas para todos os que têm em seu trabalho sua única forma de sobrevivência. Esta pressão é oriunda da exigência da qualificação, que em meio a esta situação alguns são absorvidos, exigidos, sugados, gerando para o trabalhador "um complexo monstruoso. (Maia, Lima \& Maia, 2015, p. 106).

Além das inúmeras exigências, o trabalhador moderno passa a maior parte do seu tempo disponível ao trabalho, ao patrão, e aos problemas relacionados ao ambiente de trabalho, mesmo em seu tempo livre, destinado ao seu bem-estar, o trabalhador apenas usa parar recuperar forças para um novo dia de trabalhar, conforme aponta Aranha (2012)

Sabemos que na sociedade marcada pelo imperialismo do trabalho e da razão instrumental nem sempre é fácil para o indivíduo ocupar o tempo de lazer de forma criativa, já que se encontra "achatado" na unidimensionalidade, empobrecido na capacidade de invenção, imaginação e fantasia. Com frequência o tempo livre é usado para liberar a fadiga, reproduzir práticas da moda e sucumbir ao tédio. (Aranha, 2012, p. 641).

Desta forma o processo de ensino e aprendizagem, que deveria levar os alunos à sua formação pessoal, social e intelectual, torna-se um processo de simples memorização e preparação para os testes (provas internas e externas) e em vestibulares e assume como seu objetivo a ampla aprovação e a entrada de alunos no ensino superior.

Contudo, deve-se notar que, conforme explicitou-se anteriormente, dentro da sociedade capitalista, o homem define-se conforme a quantidade de capital que possui, e só irá acumular com seu trabalho que, nos dias atuais, exigem uma maior formação, logo, a escola como reprodutora dos valores sociais em que está inserida, promove este modelo de ensino que 
sustenta a ideia de que o objetivo maior dos alunos seja entrar no ensino superior para garantir a possibilidade de melhores empregos e melhores salários.

Assim, é colocado sob os alunos grande pressão social dentro deste contexto, e torna prejudicial sua passagem pela escola e gerando o efeito chamado de ansiedade de prova. Segundo Zeidner (1998)

Examination stress and test anxiety are pervasive problems in modern society. As the information age continues to evolve, test scores will become even more important than they are today in evaluating applicants for demanding jobs and candidates for admission into highly competitive educational programs (Zeidner, 1998, p. 7).

Aponta-se então que há, dentro da estrutura de avaliação realizada no âmbito escolar, um fenômeno que traz ao aluno um efeito negativo em seu psicológico, efeito este que se dá pelo medo do resultado negativo da avaliação e pela preocupação que se dá pelas implicações futuras que os exames trazem

The topic of test anxiety has prospered, in part, due to the increasing personal importance of test situations for people in modern society, making tests and their long-term consequences significant educational, social, and clinical problems for many. Since test results in most academic and occupational settings have important practical implications for a person's goals and future career, test anxiety is frequently reported to be a meaningful factor impacting upon test scores. (Zeidner, 1998, p. 9).

Para Moreira (2018), a avaliação realizada atualmente se mostra como um problema da seguinte forma.

Professores devem preparar os alunos para a testagem, para as provas, para as respostas corretas a serem reproduzidas em exames locais, nacionais e internacionais. Internacionalmente já está consagrado o termo teaching for testing. Um absurdo, os professores são treinadores e as escolas são centros de treinamento. As melhores escolas são aquelas que aprovam mais alunos nos testes. Uma visão comportamentalista, mercadológica, massificadora. Todos os estudantes devem ser treinados para "passarem" nas mesmas provas nacionais e internacionais. Professores que não ensinam para a testagem têm a atenção chamada pela direção da escola. (Moreira, 2018, p.75).

Durante o período de avaliações, os alunos tendem a ficar com níveis de ansiedade elevados, conforme relatam Karino e Laros (2014)

Estudos brasileiros que investigaram as mudanças emocionais em situações de prova verificaram que muitos jovens que enfrentam processos seletivos não se consideravam preparados fisicamente nem psicologicamente. É comum o relato de vivência como dificuldade de concentração, inquietação, dores de cabeça, dores musculares, tonturas, além de muitos apresentarem níveis de ansiedade, estresse, medo, insegurança e aflição. (Karino \& Laros, 2014, p. 1).

E conforme esta ansiedade seja repetida, há a possibilidade de trazer ao aluno efeitos irreversíveis à saúde. Assim, o modo de avaliar e de ensinar os alunos pode adoecer alunos e trazer consequências negativas para seu desenvolvimento. No âmbito de alunos que estão próximos a prestar vestibulares, Soares (2002) explicita que no ano antecedente a realização da prova, o aluno pode sofrer vários distúrbios psicofisiológicos, chegando até mesmo a desenvolver depressão. Esta ansiedade nos alunos que estão próximos ao vestibular se dá por diversos fatores, Archer, Heumann e Filho (2001) apontam

[...] que a importância dada pelo adolescente no processo de preparação para o vestibular, ao considerá-lo um momento decisivo na sua vida, foi um fator que se associou à sensação de maior ansiedade por esses candidatos. Ainda que não bastasse, a decisão para a escolha profissional é outro fator que contribui para a geração de ansiedade. (Archer, Heumann \& Filho, 2001, p 72). 


\section{Conclusão}

Desta forma, estrutura-se dentro de um contexto social capitalista um modelo de ensino que, tira o aluno do seu papel de protagonista, prejudica seu processo de aprendizagem, mentem a ansiedade de prova constante nos jovens alunos e prejudica a formação dos jovens alunos.

Mostra-se então que, não apenas o ensino de física, mas as demais áreas da educação estão afetadas diretamente pelo modelo capitalista, prejudicando ativamente a formação destes alunos, estruturando um modelo em que atende apenas as necessidades de uma classe social e adoecendo as demais classes e cidadãos de forma geral.

Assim, se mostra necessário entender os prejuízos causados aos alunos, professores e comunidade escolar pelo modelo capitalista em que está inserida, assim deve-se buscar uma alternativa pedagógica onde o impacto do modelo social seja amenizado, onde se possa buscar um ensino de qualidade, seguro e que tenha como objetivo a formação de um cidadão pleno para questionar, participar e cumprir seu papel social.

É necessário que a escola tenha uma forma de garantir a comunidade escolar um ambiente saudável de ensino, onde sejam desenvolvidas tendências pedagógicas progressistas, onde estes alunos tomem consciência do seu papel dentro desta sociedade e possam participar ativamente na formação, e que contribuam para garantir uma ascensão social.

Pode-se pensar em futuras pesquisas onde seja investigado diretamente com os alunos esta influência negativa do modelo capitalista em sua vivência escolar, buscar através de metodologias de pesquisa investigativas ouvir as falas dos alunos, investigar sob uma perspectiva científica, de que forma os alunos e professores são afetados e quais os recursos educacionais podem ser utilizados para superar este modelo.

\section{Referências}

Archer. A. B., Heumann, S. \& Filho. S. S. L. (2011) Reflexões: Ansiedade Frente à Escolha Profissional e à Prova do Vestibular. Extensio: R. Eletr. de Extensão, ISSN 1807-0221 8(11), 70-80.

Alves. W. L. U. (2009). A história da educação no Brasil: da descoberta à lei de diretrizes e bases de 1996. Monografia. Centro Universitário Católico Salesiano Auxilium.

Andrade. R. (2010) Teoria do Capital Humano e a Qualidade da Educação Nos Estados Brasileiros. Trabalho de conclusão de curso. Universidade Federal Do Rio Grande do Sul.

Aranha. M. L. A. (2012). história da educação e da pedagogia geral e brasil.

Bizerra. F. A. (2017). expropriação do trabalho: quintessência das sociedades de classes. II Seminário Nacional de Serviço Social, Trabalho e Políticas Sociais. Universidade Federal de Santa Catarina.

Brasil. (2000) Ministério da Educação. Parâmetros Curriculares Nacionais. Ensino Médio.

Bonnewitz, P. (2005). Primeiras lições sobre a sociologia de P. Bourdieu. (2a ed). Vozes.

Freire. P. (1988). Pedagogia Do Oprimido. (18a ed). Paz e Terra

Ferreira, Jr, A. (2010). A. História da Educação Brasileira: da Colônia ao século XX. EdUFSCar. (Coleção UAB-UFSCar).

Karino. C. A. \& Laros. J. A. (2014). Ansiedade em situações de prova: evidências de validade de duas escalas. Universidade de Brasília, Brasília, Brasil Jacob A. Laros - Universidade de Brasília, Brasília, Brasil Psico-USF, 19(1), 23-36.

Libâneo. J. C. (1990). Democratização da escola pública. (19a ed).

Maia. F. E. S., Lima. F. R. S. \& Maia. F. E. S. (2015). O trabalhador, o trabalho, o capitalismo e as suas questões psicológicas. Faculdade de Ciências Médicas. Sorocaba, 17(2), 106

Marx, K. \& Engels, F. (2005) Manifesto Comunista. Boitempo Editorial.

Marx. K. (2004) Manuscritos econômicos filosóficos.

Marx. K. (1996). Os economistas.

Mészáros, I. (2005). A Educação para além do capital. Boitempo. 
Research, Society and Development, v. 10, n. 10, e536101019205, 2021

(CC BY 4.0) | ISSN 2525-3409 | DOI: http://dx.doi.org/10.33448/rsd-v10i10.19205

Mizukami, M.G. (2018). Ensino: As abordagens do processo. EPU.

Moreira, M. A. (2000). Ensino de Física no Brasil: Retrospectiva e Perspectivas. Revista Brasileira de Ensino de Física, 22(1).

Moreira, M, A. (2010). O Que É Afinal Aprendizagem Significativa?

Moreira, M. A. (2018). Uma análise crítica do ensino de Física. Estudos Avançados. 32(94).

Neto, A. B. S. (2015). A expropriação do trabalho e o desafio operário. Edufal.

Pessoa. C. (2004). Contrato didático: Sua influência na interação social e na resolução de problemas. VII Encontro Nacional de Educação Matemática. Recife.

Rego, T. C. (1995). Vygotsky: Uma perspectiva histórico-cultural da educação. Voses,

Rother, E. T. (2007). Revisão sistemática X revisão narrativa. Acta paul. Enferm.

Soares, D. H. P. (2002). Como trabalhar a ansiedade e o estresse frente ao vestibular. Em R. S. Levenfus \& D. H. P. Soares (Orgs.), Orientação Vocacional Ocupacional: Novos achados teóricos, técnicos e instrumentos para a clínica, a escola e a empresa. ArtMed.

Saviani. D. (2013). A pedagogia histórico-crítica, as lutas de classe e a educação escolar. Germinal: Marxismo e Educação em Debate, Salvador, 5(2), 25-46, dez.

Saviani. D. (1999) escola e democracia. (32a ed).

Tonet. I. (2016). Educação Contra o Capital. (3a ed).

Zeidner, M. (1998) Test anxiety: The state of the art. Plenum Press. 